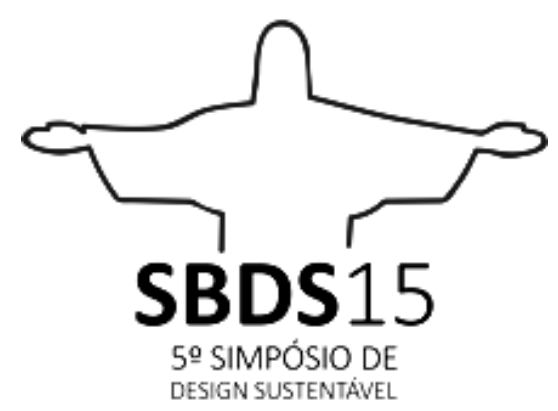

Rio de Janeiro, 11 de novembro a 13 de novembro de 2015.

\title{
JARDINS COMUNITÁRIOS DE NOVA YORK: Um método para recomendações baseado no design de experiência
}

\author{
Gabriela Varanda de Castro \\ Pontifícia Universidade Católica do Rio de Janeiro (PUC-Rio) \\ varanda.gabriela@gmail.com
}

\begin{abstract}
Resumo: Inicialmente centrado no projeto de produtos físicos, o escopo do design vem evoluindo em direção a uma perspectiva sistêmica. O principal desafio do design atualmente é desenvolver soluções para questões de alta complexidade, que exigem uma visão abrangente do projeto, envolvendo produtos, serviços e comunicação de forma conjunta, e reverter a expectativa de que a noção de bem-estar esteja necessariamente ligada à aquisição de novos artefatos, e sim baseada na qualidade do contexto. Projetos voltados para a inovação social promovem a recuperação do tecido social e ambiental, e seu bom funcionamento depende, em muito, do contexto sociocultural onde eles são implantados. Os jardins comunitários de Nova York são modelos centrados no compartilhamento do espaço público, que possibilitam experiências individuais e coexperiências, e que permitem a observação e a interpretação do significado dessas interações sociais. Este artigo considera a relação dos usuários com os jardins comunitários, com o intuito de permitir produzir recomendações de design de experiência, para potencializar a transformação nesses territórios.
\end{abstract}

Palavras-chave: design para sustentabilidade, design de experiência, transformação dos territórios, jardins comunitários.

Abstract: Initially centered on the design of physical products, the scope of design has been evolving toward a systemic perspective. The current main challenge of design is to develop solutions to issues of high complexity, requiring a comprehensive overview of the project, involving products, services and communication jointly, and reverse the expectation that the notion of wellbeing is necessarily linked to the acquisition of new artifacts, but based on the quality of the context. Projects aimed at the social innovation promote the recovery of the social and environmental fabric, and its proper functioning depends on the sociocultural context where they are deployed. Community gardens in New York are sharingcentric models of public space, which allow individual experiences and co-experiences, and also the observation and interpretation of the meaning of these social interactions. This 
paper considers the relationship of users with community gardens, in order to produce experience design recommendations to enhance the transformation of these territories.

Keywords: Design for sustainability, experience design, transformation of the territories, community gardens.

\section{INTRODUÇÃO}

O primeiro pensador, do que se convencionou chamar, mais tarde, de ecodesign, foi Victor Papanek, que assim descreveu o papel do profissional de design:

“... O designer há de ser responsável perante a ecologia e a sociedade. E há também de ser revolucionário e radical. Deve-se dedicar ao princípio do esforço mínimo da natureza, em outras palavras: um inventário mínimo orientado à diversidade máxima. Isso significa consumir menos, utilizar as coisas durante mais tempo, reciclar os materiais e possivelmente não desperdiçar papel editando livros como este." (Papanek, 1974)

Papanek afirma ainda que, na era da produção em massa, quando tudo pode ser planejado e projetado, o design se tornou uma poderosa ferramenta, com a qual modelamos nosso ambiente. Essa posição demanda uma grande responsabilidade moral e social, e um entendimento do papel do designer. Ser designer requer um alto grau de participação social (Papanek, 1974). Para promover uma visão sistêmica e integrar competências de diversos atores sociais, o design assume o papel de facilitador de mudanças, ou agente motivador de inovações, promovendo transformações e interações na sociedade.

Ecodesign, como a própria palavra indica, é a associação de duas áreas do conhecimento (ecologia e design). De uma maneira intrínseca, o ecodesign está associado a tomadas de decisão, no período de concepção de um produto ou serviço, que dizem respeito à redução de possíveis impactos ambientais causados por sua produção e pelo seu descarte. Já o termo design para sustentabilidade amplia a área de atuação do designer, incluindo a dimensão social, em projetos que podem colaborar com a transformação da sociedade, rumo a um cenário sustentável.

A proposta de novos cenários que possam corresponder a estilos de vida sustentáveis prevê que o designer deve interferir no plano cultural, apresentando novos critérios e ideias de qualidade. Manzini (2007) destaca esse nível de interferência, afirmando que embora a crise ambiental seja atualmente reconhecida e atestada, de uma maneira global, todas as medidas tomadas, até agora, diante da enorme transformação necessária no nosso modo de produção, não são suficientes para reverter o quadro atual. É necessária, então, uma descontinuidade em todas as dimensões do sistema: na dimensão física (fluxo de matéria-prima e energia), na dimensão econômica e institucional (a relação entre atores sociais) e nas dimensões ética, estética e cultural (valores e qualidades responsáveis pela legitimação social). São medidas que podem levar um curto período de tempo, ou até prazos longos, e ainda acontecer numa microescala, com simples produtos e serviços, e em grandes escalas, em sistemas sociotecnológicos globais.

Projetar soluções sustentáveis significa, portanto, definir um objetivo e desenvolver o sistema de artefatos necessário para alcançá-lo, respeitando a necessidade de redução do uso de recursos naturais e levando em conta qualidades que regenerem o tecido social.

Para Thackara (2006), o design deve se concentrar mais em como as coisas funcionam, do que (apenas) em como elas se parecem. Essa é uma mudança fundamental na relação entre pessoas que projetam coisas e aquelas que as usam. Senso e reação significam reagir a eventos num contexto - como uma cidade ou região - e ser capaz de responder rapidamente e apropriadamente quando a realidade muda. O caráter sistêmico das soluções (incluindo produtos, serviços e informações) também acentua a necessidade de repensar a cultura e a prática do 
projeto. Nessa nova visão, o papel do designer é facilitar e apoiar o desenvolvimento de inovações em uma comunidade, em um território, em uma cidade.

Argan (1992) afirma que toda cidade é um contexto, ou seja, um conjunto de textos que realiza um contexto, e que a crise do projeto na arquitetura e no urbanismo é uma crise da finalidade, do valor, é a crise da cidade moderna, que multiplica sua população até chegar a dez, quinze milhões de habitantes. Argan coloca essa questão como um problema sério de projeto, que se agravará no futuro. $E$, por isso, o projeto não pode ser simplesmente um exame dos dados objetivos e um cálculo de resistência ou preço de materiais em relação à disponibilidade financeira, mas um fator de intervenção ativa na realidade para resolver as contradições existentes. Um projeto pode ser mudado, como cada um de nós pode mudar seu comportamento segundo as circunstâncias. A crise de finalidade dos projetos, denunciada por Argan, poderia encontrar no design para sustentabilidade uma resposta para suas contradições e inquietação.

Porém, é importante que o tema da sustentabilidade não seja visto como um obstáculo, um fator limitante, e sim uma oportunidade para o aparecimento de novas ideias. Estamos ainda numa fase de transição, e o design pode ter um papel fundamental como agente transformador e facilitador de mudanças, ao lidar com a possibilidade de criação de uma nova linguagem de produtos e serviços (Castro 2008a; Castro, 2008b).

A experiência com essa nova linguagem de produtos e serviços sustentáveis envolve também novos valores simbólicos e culturais, que se relacionam profundamente com o contexto sociocultural e fenômenos contemporâneos, dimensões que dizem respeito ao nosso tempo. A construção da linguagem do design para sustentabilidade está fortemente ligada ao momento atual e à maneira como o design influencia nossa história e vice-versa (Branzi, 1989; Denis, 1998; Forty, 2007).

Cabe ao design para sustentabilidade comunicar a qualidade de produtos, serviços e sistemas voltados para esse determinado fim. A qualidade de um projeto de design pode ser verificada no que chamamos de experiência, um processo subjetivo, fortemente marcado por questões socioculturais. Todas as situações vividas pelas pessoas colaboram para formar experiências. Dessa forma, tudo poderia ser considerado "experiência". Porém, o pesquisador Nathan Shedroff afirma que há elementos que contribuem para construir experiências, que são reconhecíveis e, portanto, também projetáveis (Shedroff, 2010). O que é importante no projeto de investigação relativo à experiência é que ele enfoca as interações entre pessoas e soluções de design (Forlizzi e Battarbee, 2004).

\section{DESIGN PARA SERVIÇOS E EXPERIÊNCIA: INTERAÇÃO USUÁRIO-SOLUÇÃO}

Um dos objetivos do design voltado para inovações sociais é sugerir vocações solidárias. Aceitar partilhar soluções em um determinado território, incentivando ações de interesse coletivo, requer priorizar experiências em vez de compras materiais.

Designers podem oferecer uma perspectiva única sobre que tipos de experiências e interações usuário-solução um sistema precisa oferecer, e como elas podem mudar ao longo do tempo. Para fazer isso, designers, juntamente com outros pesquisadores, necessitam ter uma profunda compreensão do público para os quais estão projetando, além de buscar inspiração e aplicar informações e conhecimentos sobre os aspectos de como as pessoas usam e conferem significados aos produtos. A visão do designer deve ser uma das várias perspectivas dentro de uma equipe multidisciplinar, ela também tem sido descrita como empatia do design, uma variedade de perspectivas holísticas para resolver um problema de um projeto, e uma das várias perspectivas para um designer ser um "bricoleur".

As equipes de projeto multidisciplinar procuram entender e gerar tipos de interações e experiências que novos projetos e sistemas podem oferecer. Uma vez gerado um conjunto de 
experiências e interações usuário-produto, pesquisas podem ser conduzidas para entender melhor pessoas, contextos e atividades, para fornecer soluções para um problema de design.

A experiência em design para serviços convida também designers a dar nova forma a comportamentos - de pessoas, sistemas e organizações. Sua prática exige um elevado nível de "pensamento de sistema": capacidade de considerar um problema como um todo, em vez de reduzi-lo, compreender relações, bem como componentes, e sintetizar conjuntos complexos de informações e restrições (Burns et al., 2006).

O foco em interações, no design para serviços, tem sido considerá-las dentro e entre organizações, trabalhando em sistemas e redes, enquanto designers abordam cada vez mais questões da mudança organizacional e comportamental (Sangiorgi, 2009) (figura 1). Nesta evolução, o design para serviços ganhou maior credibilidade, refletindo as qualidades emergentes e interdisciplinares da disciplina (Meroni e Sangiorgi, 2011).

\section{Service Design evolution}

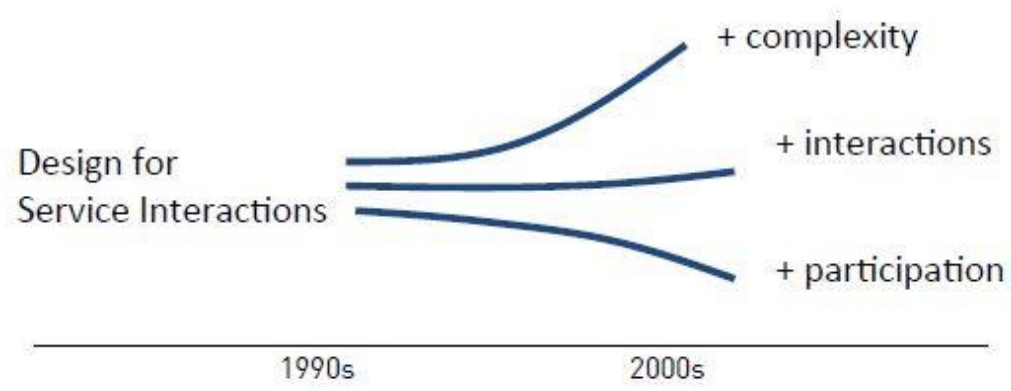

Figura 1- A evolução do design para serviços no século 21 (Sangiorgi, 2009).

Novas ideias são muitas vezes geradas por meio da interação com os usuários (inovação direcionada para o usuário), e por meio da aplicação de conhecimentos tácitos e de treinamento (figura 2). Além disso, a inovação tem sido utilizada para enfrentar os desafios da nossa sociedade, e como um catalisador da mudança social e econômica (Comissão Europeia, 2009).

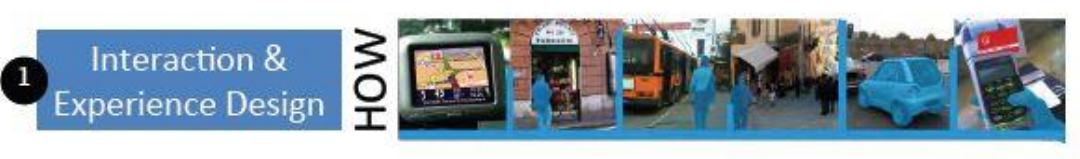

\section{$\mathfrak{t \downarrow \downarrow t}$}
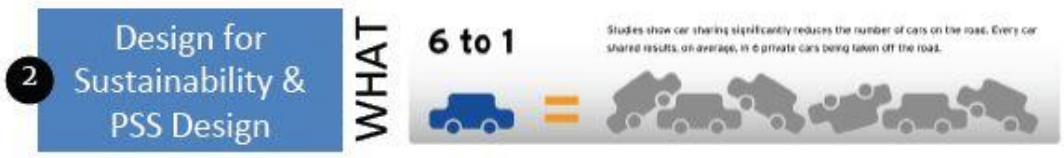

Figura 2 - A relação entre "interação e design de experiência" ("como?") e "design para sustentabilidade e sistema produto-serviço” ("o quê?”) (Sangiorgi, 2009).

A condição central para práticas transformadoras é a compreensão dos cidadãos como "agentes", e seu papel ativo na criação de bem-estar. A proposta é um modelo participativo, em que muitos dos usuários de um serviço tornam-se seus criadores e produtores, trabalhando em parceria.

O conceito de criação de plataformas também é parte da linguagem de transformação do design para serviços. Quando os participantes do projeto tornam-se cocriadores, não há entidades 
fixas e sequências de ações, permitindo maior flexibilidade e adaptação. Plataformas compostas por ferramentas delineiam as condições de determinadas práticas e de comportamentos, que emergem (Sangiorgi, 2011).

Assim como nos customer journey maps, no blueprint é possível projetar "momentos da verdade", por meio de representações dos pontos de contato, permitindo a investigação da experiência do usuário. Decisões sobre a tradicional divisão entre operações visíveis e de bastidores podem ser examinadas à luz da experiência do cliente (Wild, 2009).

Jensen e Morelli (2011) sugerem, porém, que há uma lacuna na análise que explora sistemas de serviços, que os autores chamam de "Pontos de Contato Críticos" (PCCs). Eles ilustram a utilidade da noção de PCCs no campo do design para serviços, e nos espaços de trânsito da rede contemporânea da cidade. A natureza desses pontos, gerada por essa abordagem, é imaterial, e bastante incorporada ao contexto sociocultural local. Considerando os pontos de contato, este artigo procura também ressaltar a interação entre usuários e soluções de design, e explorar com maior profundidade potenciais experiências em projetos de inovação social, utilizando um método para investigar essas interações em projetos já existentes, com o objetivo de propor recomendações para soluções futuras, identificando eixos temáticos e categorias, como veremos a seguir.

\section{A PESQUISA}

A pesquisa realizada foi qualitativa, incluiu a utilização de entrevistas com os usuários dos jardins comunitários da cidade de Nova York, e foi aplicada nos meses de fevereiro e março de 2013. A observação participante utilizou ainda registros fotográficos. A pesquisa também envolveu entrevistas com a equipe do Greenthumb, órgão da prefeitura da cidade, o objetivo foi obter informações prévias sobre os jardins comunitários a serem estudados, que foram selecionados com o apoio da instituição, e ainda para determinar como essas soluções interagem com seus associados, e compreender as questões relacionadas ao seu contexto sociocultural. Um primeiro contato com os coordenadores dos jardins selecionados foi realizado por e-mails, fornecidos pelo Greenthumb, para obter informações sobre seus membros, e os melhores dias e horários para encontrá-los nos locais. Após o mapeamento dos jardins comunitárias na cidade de Nova York (East Village), estudos de caso foram selecionados, e usuários dos jardins, entrevistados (Castro, 2014).

A aplicação do método de análise de discurso foi realizada em três jardins comunitários na cidade de Nova York, localizados no bairro do East Village (que conta hoje com cerca de 40 jardins no total): Liz Christie Community Garden, Le Petit Versailles e La Plaza Cultural (Nicolaci, 2007).

A análise dos depoimentos coletados em todas as entrevistas aconteceu em duas fases distintas: (a) a análise interparticipantes, na qual foram consideradas as respostas de todos os participantes, e (b) a análise intraparticipantes, em que o depoimento de cada um foi analisado individualmente. $\mathrm{Na}$ análise interparticipantes as respostas de todo o grupo foram sistematicamente comparadas com o intuito de se buscar recorrências. Isso foi possível pelo fato de que todos os itens do roteiro deveriam ser obrigatoriamente abordados por cada participante. Essa etapa permitiu que se tivesse uma visão geral dos depoimentos.

\subsection{Método para recomendações baseado no design de experiência}

Como pode ser confirmado pela análise do discurso das entrevistas realizadas nesta pesquisa, os jardins comunitários permitem dar legitimidade ao desejo instintivo e habilidade natural de moradores do bairro para melhorar seu ambiente físico, fornecendo uma oportunidade para a atividade de cada voluntário, um espaço físico para implantar várias iniciativas. Por resistir à tentação burocrática de ver esses espaços comunitários com uma microgestão reguladora, realizada de maneira opressora, essas organizações, ao contrário, fortalecem os indivíduos e 
responsabilizam ativistas locais, permitindo que os jardins comunitários possam contribuir para a saúde individual, promovendo a revitalização urbana e a coesão do bairro.

Os jardins comunitários podem, portanto, ser percebidos como "caminhos" e "trajetórias" internas a esses locais, de maneira que a experiência seja o foco principal da interação do usuário com o local, ou seja, uma experiência a ser vivenciada, em permanente construção, de maneira não estruturada ou com a liberdade que eles permitem. Como observado, as análises apresentadas revelam, portanto, comportamentos e motivações dos membros dos jardins comunitários. Os resultados obtidos fornecem informações sobre a "voz" de seus associados e o nível de engajamento do grupo, assim como sobre as possibilidades de interação entre os diversos membros. A identificação de pontos de interação, como "regiões de encontro ou conexão" dos seus usuários é um facilitador e funciona como "guia" ou "foco" para ativar soluções de design de experiência. Dessa forma, propomos um método, uma sequência de ações com o intuito de gerar recomendações para soluções de design de experiência, que constituiriam um arcabouço conceitual para projetos semelhantes, e também uma fonte de realimentação para aqueles em andamento (figura 3).

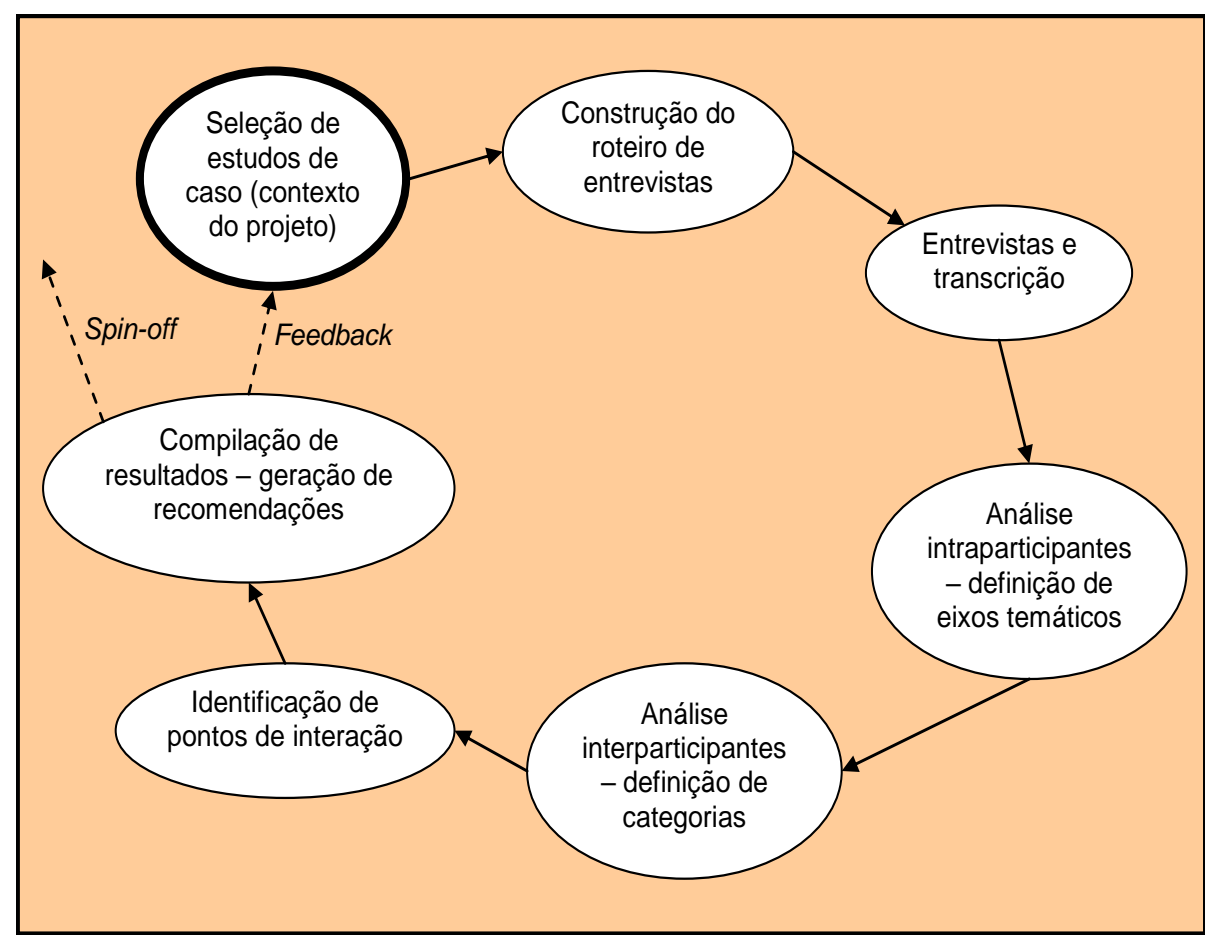

Figura 3 - Método de obtenção de recomendações prévias para soluções de design de experiência, em seus respectivos contextos socioculturais (elaborado pelo autor, baseado na pesquisa realizada).

\subsection{Eixos temáticos}

Uma leitura exaustiva e detalhada de todas as entrevistas da pesquisa de campo foi realizada, após a transcrição do áudio. Nesse processo, emergiu um conjunto de temas que se mostrou recorrente no discurso dos diversos associados dos jardins. Três eixos temáticos foram identificados e descritos, e são apresentados a seguir, com apoio de registros fotográficos.

\subsubsection{Eixo temático 1 - Jardinagem e produção de alimentos}

$\mathrm{O}$ ato de cultivar seu próprio jardim, e promover a autossuficiência e hábitos alimentares mais saudáveis, contribui para o abastecimento de alimentos das comunidades. Muitos dos jardins comunitários da cidade de Nova York estão em bairros de baixa renda, com pouco acesso a alimentos de alta qualidade, preços acessíveis ou produtos frescos, e a jardinagem pode aproximar a comunidade da alimentação mais saudável. A capacidade de garantir acesso à 
alimentação cultivada de maneira orgânica traz benefícios para diversas famílias, pessoas de todas as idades e para a cidade, como um todo (figura 4).

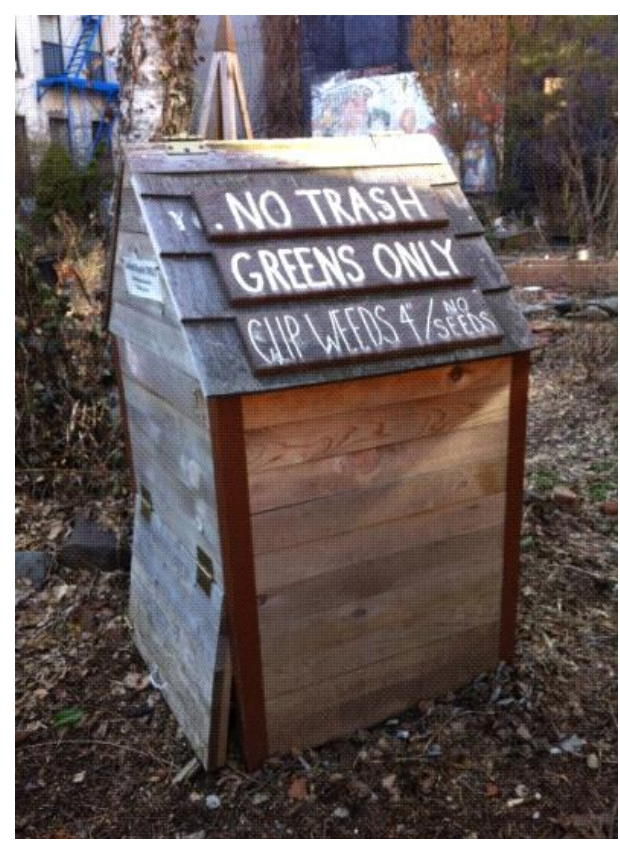

Figura 4 - Depósito de sementes (elaborado pelo autor, baseado na pesquisa realizada).

\subsubsection{Eixo temático 2 - Saúde e benefícios sociais}

A melhora do humor e a redução do estresse são alguns dos benefícios mais consistentes do contato com a natureza, por meio de estudos de investigação. Além disso, esse contato pode ser puramente visual ou sensorial, com participação ativa (caminhada, corrida, jardinagem) ou passiva (apenas de visualização). Benefícios são encontrados em várias configurações, múltiplas culturas e em todas as faixas etárias, da infância à idade adulta. Os jardins comunitários ainda apresentam temporadas de eventos, incluindo exposições de arte, música, teatro, oficinas e outros projetos. Esses tipos de atividades também ajudam a regenerar o tecido social da comunidade local (figura 5).

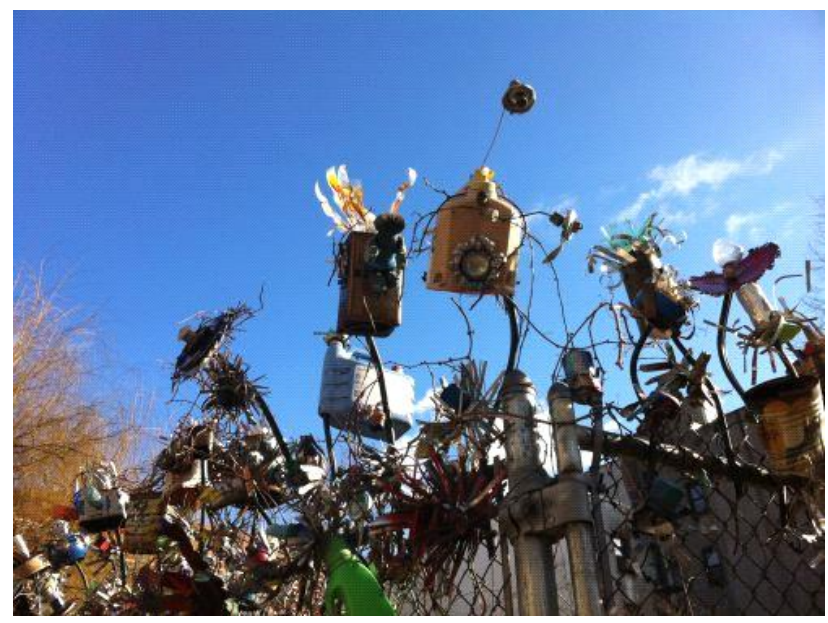

Figura 5 - Artesanato na grade de jardim comunitário (elaborado pelo autor, baseado na pesquisa realizada)

\subsubsection{Eixo temático 3 - Recreação e educação}

Ao contrário dos tradicionais parques contendo campos projetados para esportes ou equipamentos de playground, os jardins comunitários incentivam brincadeiras criativas e 
atividades em um ambiente natural, não estruturado. Fornecendo espaços seguros onde as crianças podem interagir com a natureza e entrar em contato com um grupo diversificado de várias gerações, os jardins comunitários ajudam a fornecer ingredientes essenciais de uma infância saudável (figura 6).

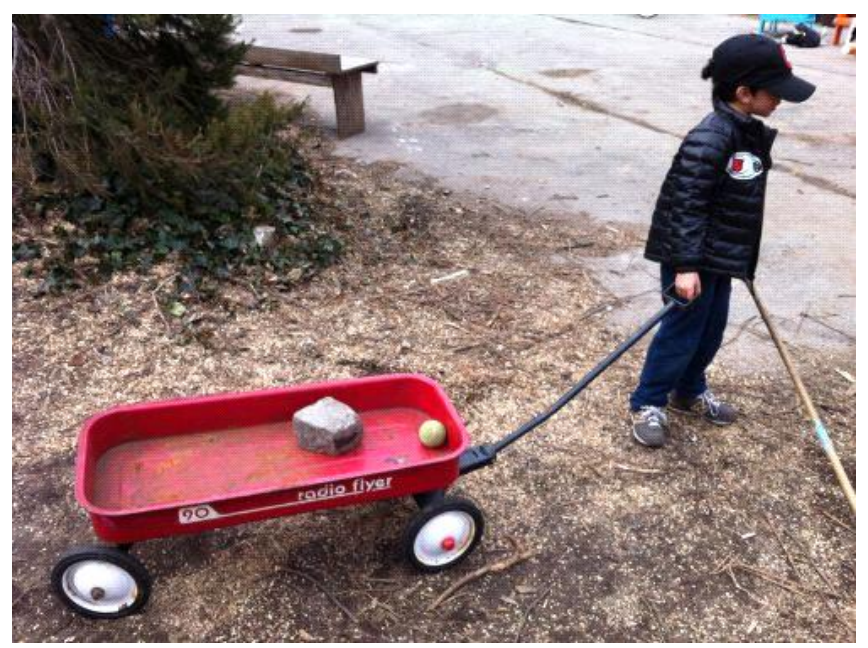

Figura 6 - Hora de brincar com os amigos (elaborado pelo autor, baseado na pesquisa realizada).

\subsection{Categorias}

Nessa etapa foi realizada ainda uma comparação das entrevistas (análise interparticipantes), e detectados pontos em comum, contradições e divergências entre as falas individuais. A partir dessa nova leitura, sete categorias foram percebidas e identificadas, como a seguir.

- Ponto de encontro: de uma maneira geral, os jardins comunitários foram vistos como locais de encontro, a exemplo da praça pública de uma cidade.

- Local de aprendizado: por reunir pessoas de diferentes formações e capacitações profissionais, os jardins permitem aos seus associados práticas espontâneas ou programadas, de aprendizado e acumulação de conhecimento.

- Voz da comunidade: os jardins comunitários permitem uma oportunidade única para expressão dos principais valores da comunidade que ali se encontra. É o lugar onde a "voz" de seus associados pode ser percebida, ou seja, o seu engajamento político e social com o local é evidenciado.

- Participação ativa nas decisões: apesar de apresentarem um número significativo de associados, a quantidade de pessoas que realmente participam da administração e da organização das atividades dos jardins comunitários é reduzida, como é revelado na fala de alguns entrevistados.

- Relação com espaço público: o reconhecimento dos jardins comunitários de Nova York como locais de uso público, cedidos pela prefeitura, inclui um série de questões relativas ao seu uso e compartilhamento corretos, e ao reconhecimento de direitos e deveres relativos a essa ocupação.

- Trabalho, lazer e voluntariado: não há salários e recompensas financeiras para quem se inscreve como membro de um jardim comunitário. Os seus associados são motivados pela vontade de criar, de maneira compartilhada, um espaço verde para suas famílias e amigos, e pela oportunidade de cultivarem canteiros e colocarem em prática suas próprias habilidades para a criação de hortas e locais de lazer.

- Oásis verde e bem-estar: verdadeiras "ilhas" de natureza, os jardins comunitários da cidade de Nova York são um refúgio para a população da cidade, que busca nesses espaços ar 
puro, tranquilidade, e uma pausa para a correria cotidiana. Apesar de seu aspecto selvagem e de não possuírem um projeto paisagístico, que Ihes confira sofisticação estética, os jardins comunitários são o resultado de um trabalho conjunto para viabilizar o verde, dentro de um ambiente de opressão urbana.

\section{CONCLUSÃO}

"Sustentabilidade social combina áreas tradicionais da política social e de princípios, tais como equidade e saúde, com questões emergentes relativas a participação, necessidades, capital social, economia, meio ambiente e, mais recentemente, com as noções de felicidade, bem-estar e qualidade de vida." (Colantonio e Dixon, 2011)

"Sustentabilidade social é um processo para a criação de lugares sustentáveis e bemsucedidos, que promovem o bem-estar, por entender o que as pessoas precisam dos lugares onde vivem e trabalham. Sustentabilidade social combina a concepção do ambiente físico com o design do mundo social, que inclui infraestrutura para apoiar a vida social e cultural." (The Young Foundation, 2010)

Para se redescobrir a qualidade de um contexto é importante que a sociedade e os profissionais de design contribuam para a construção de um mundo, onde artefatos tangíveis e intangíveis colaborem com novas demandas sociais, capazes de regenerar a qualidade do local onde se encontram.

Tradicionalmente, ferramentas de design para serviços são utilizadas para amplificar iniciativas espontâneas de comunidades como as dos jardins comunitários, aquelas que se organizam para resolver problemas e trazer soluções para o seu dia a dia, e se manter à frente dessas iniciativas. Esses projetos, que possibilitam a regeneração ambiental e social de um território, podem ter suas atividades potencializadas, com intervenções de soluções de design.

No projeto de investigação relativo ao design de experiência é possível considerar interações entre pessoas e soluções de design, e a experiência resultante dessa interação. Isso inclui todos os aspectos ao se experimentar uma solução de design, aqueles de caráter sensorial, cognitivo, emocional ou estético. A experiência de compreensão é complexa. Aceitar partilhar soluções em um determinado território é, portanto, incentivar ações de interesse coletivo.

Porém, sabe-se que muito da história de sucesso de soluções de design em comunidades é observado na interação desses projetos com seu público-alvo. Se o resultado for satisfatório, resulta numa sensação de realização, e o objetivo é alcançado. Claramente, contextos socioculturais desempenham um papel importante em como podemos sentir, expressar e modificar o significado dessa interação.

A observação participante e o método da análise do discurso são utilizados neste artigo, justamente, para entender a maneira como as pessoas organizam as suas atividades em relação à criação e ao uso dos jardins comunitários da cidade de Nova York. Eles se concentram em um entendimento comum, em torno das ações dos participantes, que podem ser observadas numa conversação ativa ou passiva.

O entendimento do funcionamento dos jardins comunitários da cidade de Nova York foi fundamental, para permitir a definição de um método capaz de gerar recomendações para projetos de design de experiência que considerem, no momento de sua criação e de seu desenvolvimento, os aspectos socioculturais locais que irão influenciar a interação entre essas soluções de design e seus usuários e, portanto, possibilitar antecipar as experiências promovidas.

Os jardins da cidade possibilitam uma alternativa de experiência diária, de uma comunidade forte. $\mathrm{O}$ jardins fazem isso naturalmente, permitindo o plantio, o posicionamento de 
esculturas, apresentações de teatro e outras manifestações artísticas, onde as crianças podem passar boa parte da sua infância. Eles constituem uma comunidade porque seus associados cooperam, colaboram e comunicam sobre o uso, a produção e a manutenção de um recurso comum, evidenciando o espaço vivido, que dá conta da qualidade que é exercida no espaço valores emocionais e significados que são imateriais.

Os jardins comunitários são o berço de memórias coletivas, símbolos culturais e história pessoal, um espaço de "temas", um local representacional. Isso permite que seu associado expresse e experimente sua cultura coletivamente, o que envolve preferências estéticas e culinárias, rituais, costumes, expressões artísticas e interações sociais.

A satisfação e a realização de uma atividade coletiva, muitas vezes, leva a uma perspectiva de autoconfiança, essencial para a tomada de decisões. Esse ato de engajamento está intimamente ligado à abordagem do impacto social e ambiental que esses grupos podem promover na sociedade, assim como a uma necessidade individual para controlar a própria vida e arredores.

Conforme visto, uma característica que confere grande liberdade a soluções de design de experiência em jardins comunitários é o fato de que esses grupos que utilizam essas áreas não foram treinados em planejamento urbano ou arquitetura. Isso permite que o associado expresse sua cultura coletivamente, decidindo sobre como esses locais serão organizados e administrados.

Um projeto de design de experiência para jardins comunitários deve considerar de antemão, portanto, a sequência de experiências acumuladas ao longo do tempo, ou seja, um histórico individual e coletivo das experiências vivenciadas dentro do jardim comunitário, levando em conta a transformação do território resultante das atividades daquele grupo, ao longo de um determinado período de tempo, prevendo, avaliando e modelando experiências futuras, em um processo contínuo e ininterrupto.

A análise das entrevistas realizadas nos jardins comunitários Liz Christy Community Garden, Le Petit Versailles e La Plaza Cultural permitiu identificar três eixos temáticos. E, dentro desses temas, foram ainda descritas, na comparação entre as entrevistas, sete categorias Para potencializar a interação dos usuários é preciso entender que esses "eixos temáticos" e "categorias" devem ser tratados como requisitos na criação de soluções de design de experiência em outros projetos, e também ativados em "pontos de contato", nas interações sociais. A identificação das "regiões de encontro ou conexão" dos usuários é um facilitador e funciona como "guia" ou "foco" para ativar essas soluções.

É possível identificar um método para gerar ações e recomendações adequadas a soluções de design para experiência, focadas na interação com seus usuários, que, quando ativadas, podem estender os resultados alcançados pelo design para serviços em processo de regeneração ambiental e social dos territórios, nos projetos de jardins comunitários.

Neste artigo, foram também realizados um estudo teórico e uma revisão bibliográfica aprofundada que permitiu relacionar temas como inovação social e design de experiência. Há ainda trabalhos relacionados interessantes de uma área recente chamada "design de ativismo", para soluções de design que buscam o engajamento social de certos grupos. Em sua intervenção no espaço urbano, essas soluções convidam à interação e à participação ativa, ao invés de simplesmente oferecer novas formas de utilizar esse espaço. Ao definir novas condições para experiências urbanas e ações das pessoas na vida diária, o "design de ativismo" é o resultado de uma construção social em curso e envolve negociações sociais, lidando com nossa percepção do campo urbano (Markussen, 2013).

\section{REFERÊNCIAS}

ARGAN, Giulio Carlo. A história na metodologia do projeto. Revista Caramelo, no 6. São Paulo: FAU/USP, 1992. 
BRANZI, Andrea. We are the primitives. In: MARGOLIN, V. (Ed.). Design discourse. Chicago: The University of Chicago Press, 1989.

BURNS, Colin at al. Transformation design. RED paper 02, London, UK: Design Council, 2006.

CASTRO, Gabriela Varanda de. Jardins comunitários de Nova York: um método para recomendações baseado no design de experiência. Rio de Janeiro, 2014. 177p. Tese de Doutorado - Departamento de Artes \& Design, Pontifícia Universidade Católica do Rio de Janeiro.

CASTRO, Gabriela Varanda de. Design de interiores e consumo: A percepção dos aspectos sócioambientais em móveis e objetos decorativos. Rio de Janeiro, 2008a. 110p. Dissertação de Mestrado - Departamento de Artes \& Design, Pontifícia Universidade Católica do Rio de Janeiro.

COLANTONIO, Aandrea; DIXON, Tim. Urban regeneration \& social sustainability - best practice from European cities. Oxford: Oxford Institute for Sustainable Development (OISD), 2011.

COMISSÃO EUROPÉIA. Challenges for EU support to innovation in services -Fostering new markets and jobs through innovation. Commission Staff Working Document, SEC (2009) 1195.

DENIS, Rafael Cardoso. Design, cultura material e fetichismo dos objetos. In: LEITE, J. S. et al (Ed.). Arcos: design, cultura material e visualidade. Rio de Janeiro: Contra Capa, 1998.

FORLIZZI, Jodi; BATTARBEE, Katja. Understanding experience in interactive systems. In: Proceedings of DISO4: Designing interactive systems: processes, practices, methods, \& techniques. 2004. p. 261-268.

FORTY, Adrian. Objetos de desejo: design e sociedade desde 1970. São Paulo: Cosac Naify, 2007.

JENSEN, Ole. B.; MORELLI, Nicolla. Critical Points of Contact: Exploring networked relations in urban mobility and service design. Danish Journal of Geoinformatics and Land Management, v. 46, n. 1, 2011, pp.36-49.

MANZINI, Ezio. Design, inovação social e desenvolvimento sustentável. Curso apresentado na Universidade Federal do Rio de Janeiro. Rio de Janeiro, 27 a 31 de ago. 2007.

MARKUSSEN, Thomas. The Disruptive Aesthetics of Design Activism: Enacting Design Between Art and Politics. Design Issues: Volume 29, Number 1 Winter, 2013.

MERONI, Anna, SANGIORGI, Daniela. Design for services. Aldershot, UK: Gower, 2011.

NICOLACI-DA-COSTA, A. M. O campo da pesquisa qualitativa e o Método de Explicitação do Discurso Subjacente (MEDS). Psicologia: Reflexão e Crítica, 20 (1), p. 65- 73, 2007.

PAPANEK, Victor. Design for the real world: Human ecology and social change. Frogmore, St. Albans: Paladin, 1974.

SANGIORGI, Daniela. Transformative services and transformation design. Second Nordic Conference on Service Design and Service Innovation (ServDes 2010). Linköping, Sweden, Dez.1-3, 2010.

SANGIORGI, Daniela. Transformative services and transformation design. International Journal of Design, 5(2), 29-40, 2011.

SHEDROFF, Nathan. Experience design. Disponível em: <http://www.nathan.com/ed/index.html>. Acesso em: 01 jun. 2010.

THACKARA, John. In the bubble: designing in a complex world. Cambrigde: MIT Press, 2006.

THE YOUNG FOUNDATION. A review of urban community land trusts in England: lessons and practical advice. London: The Young Foundation, 2010. 
WILD, Peter J. Review of Service Design Approaches. IPAS Deliverable I15.6 Report, Cambridge: University of Cambridge, Junho, 2009. 